Turró-Garriga O, Garre-Olmo J, López-Pousa S, Vilalta-Franch J, Reñé-Ramírez R, Conde-Sala JL. Abridged Scale for the Screening Anosognosia in Patients With Dementia. J Geriatr Psychiatry Neurol. 2014; 27(3): 220-226.

DOI: $10.1177 / 0891988714527515$

$\underline{\text { Abridged Scale for the Screening Anosognosia in Patients With Dementia }}$

\title{
ABRIDGED SCALE FOR THE SCREENING ANOSOGNOSIA IN PATIENTS
}

\section{WITH DEMENTIA}

Oriol Turró-Garriga, BPhych ${ }^{1}$, Josep Garre-Olmo, $\mathrm{PhD}^{1,2}$, Secundino López-Pousa $\mathrm{PhD}^{1,3,4}$, Joan Vilalta-Franch ${ }^{3,4}$, Ramón Reñé-Ramírez MD ${ }^{5}$, Josep Lluís Conde-Sala, $\mathrm{PhD}^{6}$

1. Research Unit, Institut d'Assistència Sanitària de Girona, Salt, 17190, Catalonia, Spain

2. Department of Psychology, University of Girona, Girona, 17001, Catalonia, Spain

3. Dementia Unit, Hospital Santa Caterina, Institut d'Assistència Sanitària de Girona, Salt, 17190, Catalonia, Spain

4. Department of Medicine, University of Girona, Girona, 17001, Catalonia, Spain

5. Dementia Unit, Bellvitge University Hospital, Hospitalet de Llobregat, 08907, Catalonia, Spain

6. Department of Developmental Psychology, University of Barcelona, Barcelona, 08034, Catalonia, Spain

\section{Correspondence}

Oriol Turró Garriga,

Research Unit, Institut d'Assistència Sanitària de Girona

Edifici Mancomunitat 1; Parc Hospitalari Martí i Julià

$\mathrm{C} \backslash$ Dr. Castany s/n

17190 Salt, Catalonia (Spain)

Tel. $+34.972 .182 .600 / /$ fax +34.972 .189 .017$

oriol.turro@ias.cat

Total words: 2,848

Tables: 2

Figures: 1 


\section{Abstract}

The objective of this cross-sectional study was to validate an abridged version of the Anosognosia Questionnaire - Dementia (AQ-D) for screening anosognosia in daily practice. The authors reduce the AQ-D from 30 items to 9, with a large sample of Alzheimer's disease (AD) patients $(\mathrm{n}=352)$. The Cronbach's alpha was 0.793 and an area under the COR curve was 0.946. Kappa index between new Abridged AQ-D $(\mathrm{AAQ})$ and original AQ-D was $=0.800$. The AAQ presents good validity and reliability indicators and kept concordance with the original scale. It is quick and easy to administer and it can simplify the clinical screening of anosognosia in AD patients.

KEYWORDS: Alzheimer disease [MeSH], Awareness [MeSH], Neuropsychological Tests [MeSH], Agnosia [MeSH], Dementia [MeSH], Cognitive Disorders [MeSH] 


\section{Introduction}

The construct of anosognosia in dementia is evolving very fast, and while some studies analyze the neurological and neuropsychological correlates of anosognosia in cognitive impairment, others use the latest neuroimaging technologies to identify structural or functional disruptions that may explain the lack of disease awareness in some patients with Alzheimer's disease ${ }^{1-4}$.

Consequences of anosognosia on both the patient and the caregiver are widely known. In 1914, Babinski ${ }^{5}$ described this disorder in post-stroke hemiplegic patients, and later on, it has been described in a variety of pathologies ${ }^{5-8}$. The prevalence of anosognosia ranges between 11 and $70 \%$ in Alzheimer's disease, and has been associated with more severe cognitive impairment, although it can be seen in early stages too ${ }^{9-10}$.

Anosognosia has also been associated with increased frequency and severity of behavioral and psychological symptoms of dementia, mainly with apathy, disinhibition, irritability, and delusions ${ }^{11-13}$. The main consequences of anosognosia are increased risk behaviors, lower treatment adherence, and increased difficulties for the family to manage the patient. In this sense, the presence of anosognosia has been associated with higher caregiver burden and increased institutionalization ${ }^{14-16}$.

Given the significant impact of anosognosia on the patients and their environment, performing a systematic assessment in clinical practice would be advisable. However, there is a lack of quick and reliable tools to perform a screening, which would allow selecting those patients requiring further evaluation of anosognosia and its clinical consequences. Among the available tools to assess anosognosia, there are some brief classic subjective scales, such as the Experimenter Rating Scale or the Anosognosia 
Rating Scale, but they require the physician to perform a wide exploration before a classification can be made ${ }^{17-18}$. Usually, the questionnaires for the assessment of anosognosia analyze the discrepancies detected between the patient's and the caregiver's reports ${ }^{9}$. Among these scales, the most commonly used, especially in research, is the Anosognosia Questionnaire - Dementia (AQ-D), because it includes a cognitive and functional assessment of the patient, and also takes into consideration changes in behavior ${ }^{19-20}$. Nevertheless, this questionnaire has 30 items, and its administration requires too much time to be used as a routine screening tool.

Therefore, the aim of this study was to confirm that the abbreviated version of the AQ-D is a valid instrument to screen for the presence of anosognosia in concordance with the original questionnaire, which would provide a tool allowing a quick and reliable diagnosis of anosognosia in clinical practice.

\section{Methods}

Design: A cross-sectional, observational, and analytical study

\section{Patients}

The sample set comprised patients with mild, moderate, and severe AD who were diagnosed at two different memory clinics (Hospital Santa Caterina in Girona (HSC), Spain and Hospital Universitari de Bellvitge in Barcelona (HUB), Spain). Patients with probable AD according to the criteria outlined by the National Institute of Neurological and Communicative Disorders and Stroke - Alzheimer's Disease and Related Disorders Association $^{21}$ who had a close, reliable caregiver capable of answering the questions about their states, and who were not institutionalized, were included. The study protocol 
was approved by the Institutional Review Board of each hospital and all the participants signed the informed consent form.

\section{Procedure and instruments}

In a single study visit, patients were assessed by a trained psychologist that scored the patients according to a scale (described below), administered questionnaires, and registered the clinical information from the clinical chart of each patient.

The AQ-D is a questionnaire comprised of 30 Likert-type response items with four response options (never, sometimes, often, and always) with a score ranging from 0 to 90 points. The presence of anosognosia is determined by a difference between the caregiver's and the patient's score greater than 32 points. The AQ-D has a high internal consistency $($ Cronbach alpha $=0.91)$ and a good inter-examiner reliability (Charlson comorbidity index $=0.90)^{20}$. The factor structure includes two factors, a cognitivefunctional factor and a behavioral factor, which explain $38.9 \%$ of the total variance ${ }^{19}$.

The data on the sociodemographic characteristics (age, gender, scholarship, civil status, and place of residence) of patients and caregivers were collected in a standardized questionnaire. The clinical assessment of patients was carried out using the following 4 scales. The Mini-Mental State Examination (MMSE) is a screening test for cognitive impairment. It has a score range of 0 to 30 , with a lower score indicating greater cognitive impairment ${ }^{22}$. The Disability Assessment in Dementia (DAD) ${ }^{23}$ is a specific functional disability assessment scale for patients with dementia that is administered to the caregiver. It is comprised of 40 dichotomous (yes/no) questions that assess the ability of the patient to execute 17 basic activities of daily living and 23 instrumental activities. "Yes" is scored as one and "no" is scored as 0 , giving a score range of 0 to 40 points. The Neuropsychiatric Inventory (NPI) ${ }^{24}$ is a validated method 
for the assessment of the presence of behavioral and psychological symptoms of dementia (BPSD). It is filled out by the caregiver and consists of 12 subscales in which the frequency and severity of delusions, hallucinations, agitation, depression/dysphoria, anxiety, euphoria, apathy, disinhibition, irritability, motor disturbances, sleep disorders and eating disorders are assessed. The score is the product of the frequency (range $=1-$ 4) and the severity (range $=1-3$ ) of the symptoms, with the total score ranging from 0

to 144 points. The Global Deterioration Scale (GDS) ${ }^{25}$, which ranges from 1 (no cognitive decline) to 7 (severe cognitive decline) assesses the stage of disease progression of the patient with dementia. The GDS-4 includes cases of mild dementia, the GDS-5 includes cases of moderate dementia, and the GDS-6 includes cases of moderate-severe dementia.

\section{Statistical analysis}

An extensive analysis of the results was performed by both absolute and relative frequencies for qualitative variables, or by central tendency and dispersion measurements for quantitative variables.

New variables were created from the difference between the caregiver's and patient's score in each of the 30 Likert-type response items. From these new variables, we carried out an exploratory factor analysis (EFA) with Promax rotation (which allows for correlation between the factors) and constraining the resulting factor structure to two factors, to maintain the structure of the original scale ${ }^{18}$. We constructed the abridged questionnaire by selecting the variables with an absolute difference in the eigenvalues of the two factors $\geq 0.60^{26}$.

The internal consistency of the abridged questionnaire was evaluated using the Cronbach alpha coefficient. The level for acceptable reliability was an alpha coefficient 
$\geq 0.7$. A new EFA of the abbreviated questionnaire was carried out to compare the factor structure with the original AQ-D factor structure. To determine the cut-off points for the abridged questionnaire, ROC curves were used. The area under the curve (AUC), as well as the sensitivity and specificity of each cut-off point, were determined for all adjusted ROC curves. The optimal cut-off point was established based on the maximum sum of sensitivity and specificity.

We compared the validity of the criteria for the AQ-D and the Abridged Anosognosia Questionnaire (AAQ) by calculating the kappa index. The convergent validity and discriminant validity were assessed by calculating the Pearson or Spearman's correlation coefficient with the MMSE, DAD and NPI scales for the overall score of the abridged questionnaire and the score of each factor.

The results are expressed as absolute numbers, percentages, averages, standard deviations, and 95\% confidence intervals (CIs). The level of statistical significance was set at 0.05 to test hypotheses. All data processing and analysis was performed using SPSS version 17.0 for Windows.

\section{Results}

We studied a sample of 352 patients with $\mathrm{AD}, 69 \%$ of which were women, with a mean age of 79.2 years $(\mathrm{SD}=6.6)$, of which $53.5 \%$ of the cases had a level of education below basic studies, $36.4 \%$ had primary studies, and $9.9 \%$ had middle or higher studies. The mean age of the primary caregivers was of 61.4 years $(\mathrm{SD}=13.7)$. Most were women $(69.3 \%)$, and $43.8 \%$ of the caregivers were the patients' spouses and the rest 
were the children $(51.0 \%)$ or other relatives $(5.2 \%)$. The clinical and sociodemographic data of the sample are described in Table 1.

The mean score in the AQ-D was 29.4 points $(\mathrm{SD}=20.3$; range $=-19.0-88.0)$. The prevalence of anosognosia according the AQ-D score (discrepancy $\geq 32$ points) was $45.7 \%(95 \% \mathrm{CI}=41.0-52.5)$.

The FA applied to the AQ-D explained $56.2 \%$ of the variance. There were nine items with an eigenvalue difference $\geq 0.60$ between two factors and these items were selected as representative questions from the abbreviated AQ-D scale (Table 2). The wording of each of the nine items of the new AAQ is also in Table 2.

The EFA applied to the AAQ also grouped the items into two factors, explaining $57.9 \%$ of the variance, and maintaining the factor structure of the original AQ-D. The internal consistency of the AAQ was within acceptable limits (Cronbach alpha $=0.793$ ). For the first factor, the Cronbach alpha was 0.815 and the second factor was 0.627 , with an AUC of 0.946. The presence of anosognosia was established when there was a difference of $\geq 13$ points between the caregiver's and patient's responses, with a sensitivity and specificity that when compared to the original scale was above 0.8 (0.909 and 0.859, respectively).

The prevalence of anosognosia diagnosis with the AAQ was $47.2 \%(95 \% \mathrm{CI}=$ 41.8-52.5). When compared side-by-side with the AQ-D, the validity of the criteria for the AAQ was acceptable, with a kappa index $=0.800(\mathrm{CI} 95 \%=0.737-0.863)$. Figure 1 shows the ROC curve for the AAQ (AUC $=0.946)$. Since samples from two different sites were available, a comparative study was carried out separately using the data from each site. The results showed agreement for both HSC and HUB, kappa $=0.800$ and kappa $=0.776$, respectively. The analysis of the construct discriminant validity of the 
factors showed an inverse correlation between MMSE scores and the first factor (cognitive and functional) in both patients with anosognosia (Spearman's rho $=-0.215$; $p=0.015)$ and without (Spearman's rho $=-0.194 ; p=0.008$ ). Similar results were obtained between the DAD scale and the first factor for patients with (Spearman's rho= $-0.314 ; \mathrm{p}<0.001$ ) and without (Spearman's rho $=-0.184 ; \mathrm{p}=0.012$ ) anosognosia. A direct correlation was detected between the second factor (behavioral) and the NPI scores in patients with and without anosognosia (Spearman's rho $=0.445 ; \mathrm{p}<0.001$ and Spearman's rho $=0.198 ; p=0.007$, respectively), and it was stronger in the former. In the analysis of the construct discriminant validity, the AAQ score showed significant differences in each of the stages of the GDS $(F=34.6 ; g l=2 ; p<0.001)$. Spearman's correlation coefficients were moderate to high with the NPI scale (rho $=0.573 ; p$ $<0.001$ ) and the DAD scale (rho $=-0.333 ; \mathrm{p}<0.001$ ) and, to a lesser extent, with the MMSE (rho $=-0.167 ; p=0.002$ ). Regarding sociodemographic characteristics, the previously detected differences using the original scale were still observed, thus, cases with anosognosia were older ( $\mathrm{U}$ Mann Whitney $=12,313.0 ; \mathrm{p}=0,008$ ), but no differences in the gender, civil status and education were detected (gender: $\chi^{2}=0,012$; $\mathrm{gl}=1 ; \mathrm{p}=0,934$. Civil status: $\chi^{2}=2,129 ; \mathrm{gl}=3 ; \mathrm{p}=0,345$. Education: $\chi^{2}=0,911 ; \mathrm{gl}=2$; $\mathrm{p}=0,637$ ). Regarding the residence of the caregivers, as when evaluated with AQ-D, sons lived more frequently with the patients with anosognosia $\left(\chi^{2}=11,5 ; g l=1 ; p=0,001\right)$.

\section{Discussion}

Anosognosia is frequently diagnosed in those suffering from AD. Despite this, it is poorly studied in daily clinical practice, mainly due to the lack of defined diagnostic criteria. Specifically, there is disagreement on whether to consider anosognosia a focal 
or global disorder, as well as there being a discrepancy between the dimensional and dichotomic (presence/absence) assessments ${ }^{27-29}$. These aspects are directly associated with the use of different methodologies and instruments for assessment ${ }^{30-31}$.

The selection of the AQ-D for the study of anosognosia was carried out based on the fact that it discriminates between patients with minimal alterations of awareness of the disease and patients who clearly present with anosognosia. Also, the AQ-D is a scale that was developed for detecting anosognosia globally ${ }^{19}$, incorporating the assessment of cognitive disorders, as well as functional and behavioral disorders ${ }^{18}$. Despite its use by different research groups ${ }^{32-33}$, the use of the AQ-D in the context of clinical practice is not common and the clinical diagnosis of anosognosia continues to be through clinical anamnesis. One reason is that there is a lack of a gold standard test that allows for definite distinction between patients with and without anosognosia. Another limiting factor is the lack of a test that is easy to use and quick to administer. The AAQ satisfies these requirements and provides a more comprehensive and standardized way to assess anosognosia.

The results reported here have shown that the AAQ is equivalent to the original scale and that it identifies the presence of anosognosia in patients with AD accurately. We note that the items selected in the AAQ correctly evaluate memory loss, an aspect that is frequently assessed in different scales for evaluating cognitive impairment in AD patients. Remembering events or remembering the shopping list and the ability to use currency are items of the cognitive assessment (part A) of the Blessed Dementia Rating Scale (BDRS) ${ }^{34}$, one of the scales most used in the diagnosis and follow-up of AD. The items remembering telephone calls and ability to carry out transactions are included in the functional evaluation scale of the Disability Assessment in Dementia ${ }^{23}$, which is 
widely used in studies and clinical trials. Likewise, the items being more self-seeking and being more irritable are items that are a part of section $\mathrm{C}$ (behavioral subscale) of the BDRS.

The frequency and severity of the BPSD is high in patients with anosognosia. The AAQ correlates well with the presence of BPSD as previous studies have indicated, showing a high association with frontally mediated disorders ${ }^{11,}{ }^{12}$. The $33.8 \%$ of the study patients who were in a mild or initial phase of disease stage were found to have a strong correlation between anosognosia and behavioral disorders including irritability, apathy and disinhibition, disorders associated with the alteration of the abilities of planning and organizing ${ }^{34}$. This aspect is important, as the presence of dysexecutive disorders in the initial phases of anosognosia may lead to a greater exposure of the patients to higher risk behaviors and making poor decisions that may affect the patients themselves as well as the people around them ${ }^{2,14}$. This highlights the importance of studying anosognosia in daily clinical practice, both for adjusting the pharmacological and non-pharmacological treatments, as well as avoiding risky situations and adjusting strategies of psychoeducational support to relatives.

Scale abbreviation, which is typically done for scales that are used frequently, is a common technique that is done to facilitate the care and supervision of patients in clinical practice. Currently, there are condensed versions of scales as common as the Neuropsychiatric Inventory, the Geriatric Depression Scale, and the Burden Interview, among others ${ }^{34-38}$, which has made it easier to include them in research protocols, during clinical care, and during socio-sanitary care. In addition to the AAQ being in agreement with the original scale, it has excellent sensitivity and specificity rates. The new AAQ scale preserves the structure of two factors with the items, the first of which 
is associated with cognitive and functional abilities, and the second is related to behaviour. Moreover, the correlations existing between the first factor (cognitive and functional) and the MMSE score, and between the second factor (behaviour) and the NPI score, not only increase the discriminating validity of the factors, but also support the decision to force the result of the first FA. It should be noted that while the cut-off point selected in the AAQ has high values of sensitivity and specificity compared to the original scale, it also has a greater sensitivity than the AQ-D, a feature that should be taken into account during the study of anosognosia.

One limitation in this AAQ validation study is that the sample set was not specifically selected for this purpose. However the inclusion of AD patients in different stages of disease progression was taken into account (as was the case in the original factor structure validation study). Another limitation was in the determination of the items of the AAQ, as there are multiple forms for this purpose. In this study, we prioritized the factor structure of the original scale presented with a composition of two factors. However, the indexes of concordance with the original scale demonstrate that the items selected are adequate and the factor structure has been maintained. Importantly the number of items is sufficiently reduced to render the abbreviated scale more practical than the original scale. In addition, the two items comprising the two factor scale refer to aspects easily observed clinically in dementia patients.

Currently, pressure on health care services makes it difficult to expand the study of patients, and the use of psychometric instruments is being reduced to the essential minimums. The incorporation and use of new scales is directly correlated to the time of administration and to the information it provides ${ }^{39}$. Under these circumstances, for the 
study of anosognosia, the use of the AAQ is advisable, as it allows a valid and reliable diagnosis to be reached more swiftly.

Acknowledgments: We would like to thank Dr. Sergio E. Starkstein for providing the scale in Spanish and his supporting review of the study, and Dr. Joan Vilalta-Franch, Dr. Jordi Gascón-Bayarri, Montserrat Juncadella-Puig \& Dr. Laia Calvó-Perxas for their support as members of the staff of HSC and HUB.

Author's contribution: This study is part of the doctoral thesis of the first author in the Department of Psychiatry and Legal Medicine of the Autonomous University of Barcelona. All authors contributed equally to the preparation of this article. Statistical analyses were performed mainly by Dr. Josep Garre-Olmo and Mr. Oriol Turró-Garriga.

Funding: This study was partially conducted within the framework of the project: Assessing perceptions of patient quality of life in patients with Alzheimer's disease and their family caregivers over a two-year period funded by Spain's Ministry of Science and Innovation (reference PSI2010-19014). 


\section{References}

1. Orfei MD, Varsi AE, Blundo C, Celia E, Casini AR, Caltagirone C, Spalletta G. Anosognosia in mild cognitive impairment and mild Alzheimer's disease: frequency and neuropsychological correlates. Am J Geriatr Psychiatry. 2010;18:1133-40

2. Markova IS, Berrios GE. The 'object' of insight assessment: relationship to insight 'structure'. Psychopathology. 2001;34:245-252.

3. Clare L, Whitaker CJ, Nelis SM, Martyr A, Markova IS, Roth I, Woods RT, Morris RG. Multidimensional Assessment of Awareness in Early-Stage Dementia: A Cluster Analytic Approach. Dement Geriatr Cogn Disord. 2011;31:317-27.

4. A Michon, B Deweer, B Pillon, Y Agid, B Dubois. Relation of anosognosia to frontal lobe dysfunction in Alzheimer's disease. J Neurol Neurosur Psych. 1994;57:805-809.

5. Babinski J. Contribution à l'étude des troubles mentaux dans l'hémiplégie organique cérébrale (anosognosie). Rev Neurol (Paris). 1914;27:845-848.

6. Ecklund-Johnson E, Torres I. Unawareness of deficits in Alzheimer's disease and other dementias: operational definitions and empirical findings. Neuropsychol Rev. 2005;15:147-166.

7. Medalia A, Thysen J. Insight Into Neurocognitive Dysfunction in Schizophrenia. Schizophr Bull. 2008;34:1221-1230.

8. Jenkinson PM, Preston C, Ellis SJ. Unawareness after stroke: a review and practical guide to understanding, assessing, and managing anosognosia for hemiplegia. J Clin Exp Neuropsychol. 2011;33:1079-93 
9. Leicht H, Berwig M, Gertz HJ. Anosognosia in Alzheimer's disease: the role of impairment levels in assessment of insight across domains. J Int Neuropsychol Soc. 2010;16:463-473.

10. Clare L. The construction of awareness in early-stage Alzheimer's disease: a review of concepts and models. Br J Clin Psychol. 2004;43:155-175.

11. Spalletta G, Girardi P, Caltagirone C, Orfei MD. Anosognosia and neuropsychiatric symptoms and disorders in mild Alzheimer disease and mild cognitive impairment. J Alzheimers Dis. 2012;29:761-772.

12. Conde-Sala JL, Reñé-Ramírez R, Turró-Garriga O, Gascón-Bayarri J, JuncadellaPuig M, Moreno-Cordón L, Viñas-Diez V, Garre-Olmo J. Clinical differences in patients with Alzheimer's disease according to the presence or absence of anosognosia: implications for perceived quality of life. J Alzheimers Dis. 2013;33:1105-16.

13. Kashiwa Y, Kitabayashi Y, Narumoto J, et al. Anosognosia in Alzheimer's disease: association with patient characteristics, psychiatric symptoms and cognitive deficits. Psychiatry Clin Neurosci. 2005;59:697-704.

14. Starkstein SE, Jorge R, Mizrahi R, et al. Insight and danger in Alzheimer's disease. Eur J Neurol. 2007;14:455-460.

15. Aalten $\mathrm{P}$, van Valen E, de Vugt ME, et al. Awareness and behavioral problems in dementia patients: a prospective study. Int Psychogeriatr. 2006;18:3-17.

16. Turro-Garriga O, Garre-Olmo J, Vilalta-Franch J, et al. Burden associated with the presence of anosognosia in Alzheimer's disease. Int J Geriatr Psychiatry. 2013;28:291-297. 
17. Reed BR, Jagust WJ, Coulter L. Anosognosia in Alzheimer's disease: relationships to depression, cognitive function, and cerebral perfusion. J Clin Exp Neuropsychol. $1993 ; 15: 231-244$.

18. Bisiach E, Vallar G, Perani D, et al. Unawareness of disease following lesions of the right hemisphere: anosognosia for hemiplegia and anosognosia for hemianopia. Neuropsychologia. 1986;24:471-482.

19. Migliorelli R, Tesón A, Sabe L, Petracca G, Petracchi M, Leiguarda R, et al. Anosognosia in Alzheimer's disease: A study of associated factors. J Neuropsychiatry Clin Neurosci. 1995;7:338-344.

20. Starkstein SE, Sabe L, Chemerinski E, et al. Two domains of anosognosia in Alzheimer's disease. J Neurol Neurosurg Psychiatry. 1996;61:485-490.

21. McKhann G, Drachman D, Folstein M, et al. Clinical diagnosis of Alzheimer's disease: report of the NINCDS-ADRDA Work Group under the auspices of Department of Health and Human Services Task Force on Alzheimer's Disease. Neurology. 1984;34:939-944.

22. Folstein MF, Folstein SE, McHugh PR. "Mini-mental state". A practical method for grading the cognitive state of patients for the clinician. J Psychiatr Res. $1975 ; 12: 189-198$.

23. Gelinas I, Gauthier L, McIntyre M, Gauthier S. Development of a functional measure for persons with Alzheimer's disease: the disability assessment for dementia. Am J Occup Ther. 1999;53:471-481.

24. Cummings JL, Mega M, Gray K, et al. The Neuropsychiatric Inventory: comprehensive assessment of psychopathology in dementia. Neurology. 1994;44:2308-2314. 
25. Reisberg B, Ferris SH, de Leon MJ, Crook T. The Global Deterioration Scale for assessment of primary degenerative dementia. Am J Psychiatry. 1982;139:11361139.

26. Kim JO, Mueller CW. Factor analysis. Statistical methods and practical issues. In Series on Quantitative Applications in the Social Sciences. Sage University Paper: Beverly Hills, 1978. CA.

27. Arkin S, Mahendra N. Insight in Alzheimer's patients: results of a longitudinal study using three assessment methods. Am J Alzheimers Dis Other Demen. 2001;16:211224.

28. Ansell EL, Bucks RS. Mnemonic anosognosia in Alzheimer's disease: a test of Agnew and Morris (1998). Neuropsychologia. 2006;44:1095-1102.

29. Hannesdottir K, Morris RG. Primary and secondary anosognosia for memory impairment in patients with Alzheimer's disease. Cortex. 2007;43:1020-1030.

30. Agnew S, Morris R. The heterogeneity of anosognosia for memory impairment in Alzheimer's disease: a review of the literature and a proposed model. Aging Ment Health. 1998;2:7-19.

31. Clare L, Markova I, Verhey F, Kenny G. Awareness in dementia: A review of assessment methods and measures. Aging Ment Health. 2005;9: 394-413.

32. Sato J, Nakaaki S, Murata Y, et al. Two dimensions of anosognosia in patients with Alzheimer's disease: reliability and validity of the Japanese version of the Anosognosia Questionnaire for Dementia (AQ-D). Psychiatry Clin Neurosci. $2007 ; 61: 672-677$. 
33. Blessed G, Tomlinson BE, Roth M. The association between quantitative measures of dementia and of senile change in the cerebral grey matter of elderly subjects. Br J Psychiatry. 1968;114:797-811.

34. Vasterling JJ, Seltzer B, Watrous WE. Longitudinal assessment of deficit unawareness in Alzheimer's disease. Neuropsychiatry Neuropsychol Behav Neurol. 1997;10:197-202.

35. Bedard M, Molloy DW, Squire L, et al. The Zarit Burden Interview: a new short version and screening version. Gerontologist. 2001;41:652-657.

36. Kaufer DI, Cummings JL, Ketchel P, et al. Validation of the NPI-Q, a brief clinical form of the Neuropsychiatric Inventory. J Neuropsychiatry Clin Neurosci. 2000;12:233-239.

37. Ortega-Orcos R, Salinero-Fort MA, Kazemzadeh-Khajoui A, et al. Validation of 5 and 15 items Spanish version of the geriatric depression scale in elderly subjects in primary health care setting. Rev Clin Esp. 2007;207:559-562.

38. Sheikh JI, Yesavage JA. Geriatric Depression Scale (GDS): Recent evidence and development of a shorter version. Clin Gerontol. 1986;5:165-172.

39. Banerjee S, Wittenberg R. Clinical and cost effectiveness of services for early diagnosis and intervention in dementia. Int J Geriatr Psychiatry. 2009;24:748-754. 
Table 1. Clinical and sociodemographic characteristics of patients.

\section{TOTAL}

\begin{tabular}{|c|c|}
\hline \multicolumn{2}{|l|}{$\mathbf{N}=352$} \\
\hline Age, mean (SD) & $79.2(6.6)$ \\
\hline Gender-female-, n (\%) & $98(69.0)$ \\
\hline \multicolumn{2}{|l|}{ Civil status, n (\%) } \\
\hline Married & $226(64.2)$ \\
\hline Widow/widower & $117(33.2)$ \\
\hline Other & $9(2.6)$ \\
\hline \multicolumn{2}{|l|}{ Education*, n (\%) } \\
\hline Illiterate & $32(9.1)$ \\
\hline Low & $156(44.4)$ \\
\hline Elementary & $128(36.4)$ \\
\hline High & $35(9.9)$ \\
\hline \multicolumn{2}{|l|}{ Place of residence, $\mathrm{n}(\%)$} \\
\hline Private & $292(83.0)$ \\
\hline Relative & $55(15.6)$ \\
\hline Institution & $5(1.4)$ \\
\hline \multicolumn{2}{|l|}{ GDS, n (\%) } \\
\hline 4-mild & $196(55.7)$ \\
\hline 5-moderate & $123(34.9)$ \\
\hline 6 -severe & $33(09.4)$ \\
\hline MMSE, mean (SD) & $17.7(5.1)$ \\
\hline DAD, mean $(\mathrm{SD})$ & $60.9(11.1)$ \\
\hline NPI, mean (SD) & $21.5(19.6)$ \\
\hline Delusions & $1.2(2.7)$ \\
\hline Hallucinations & $0.4(1.6)$ \\
\hline Agitation & $1.7(0.2)$ \\
\hline Depression & $2.2(3.1)$ \\
\hline Anxiety & $1.9(3.2)$ \\
\hline Euphoria & $0.5(1.5)$ \\
\hline Apathy & $4.5(4.3)$ \\
\hline Disinhibition & $1.2(2.5)$ \\
\hline Irritability & $2.8(3.6)$ \\
\hline Behavioral disturbances & $1.6(3.3)$ \\
\hline Sleep disorders & $1.1(2.7)$ \\
\hline Eating disorder & $2.3(4.8)$ \\
\hline
\end{tabular}

NOTE: $*$ The scholarship of the patient could not be established in one case.GDS $=$ Global Deterioration Scale; MMSE = Mini-Mental State Examination; DAD = Disability Assessment in Dementia; NPI = Neuropsychiatric Inventory. 
Table 2. Matrix of the results of the analysis of main components with Promax rotation and Kaiser normalization.

\begin{tabular}{|c|c|c|c|}
\hline ITEMS & F1 & F 2 & Dif* \\
\hline 1. Do you have problems remembering the date? & 0.696 & -0.147 & 0.5 \\
\hline 2. Do you have problems orienting yourself in new places? & 0.694 & -0.157 & 0.5 \\
\hline 3. Do you have problems remembering telephone calls? & 0.823 & -0.132 & 0.7 \\
\hline 4. Do you have problems understanding conversations? & 0.235 & 0.518 & -0.3 \\
\hline 5. Do you have problems signing your signature? & 0.287 & 0.270 & 0.0 \\
\hline $\begin{array}{l}\text { 6. Do you have problems understanding what you read in } \\
\text { the newspaper? }\end{array}$ & 0.478 & 0.247 & 0.2 \\
\hline $\begin{array}{l}\text { 7. Do you have problems keeping your personal belongings } \\
\text { in order? }\end{array}$ & 0.555 & 0.076 & 0.5 \\
\hline $\begin{array}{l}\text { 8. Do you have problems remembering where you leave } \\
\text { things in your home? }\end{array}$ & 0.736 & -0.046 & 0.7 \\
\hline 9. Do you have problems writing notes or letters? & 0.530 & 0.161 & 0.4 \\
\hline 10. Do you have problems to use handling money? & 0.740 & -0.040 & 0.7 \\
\hline $\begin{array}{l}\text { 11. Do you have problems orienting yourself in your } \\
\text { neighborhood? }\end{array}$ & 0.486 & 0.171 & 0.3 \\
\hline 12. Do you have problems remembering appointments? & 0.767 & -0.156 & 0.6 \\
\hline 13. Do you have problems practicing your favorite hobbies? & 0.573 & 0.189 & 0.4 \\
\hline 14. Do you have problems communicating with people? & 0.204 & 0.522 & -0.3 \\
\hline 15. Do you have problems doing mental calculations? & 0.408 & 0.241 & 0.2 \\
\hline $\begin{array}{l}\text { 16. Do you have problems remembering things you have to } \\
\text { buy when you go shopping? }\end{array}$ & 0.858 & -0.199 & 0.7 \\
\hline 17. Do you have problems controlling your sphincters? & 0.057 & 0.392 & -0.3 \\
\hline 18. Do you have problems understanding the plot of a & 0.566 & 0.158 & 0.4 \\
\hline
\end{tabular}


movie?

19. Do you have problems orienting in your house?

$\begin{array}{lll}0.139 & 0.315 & -0.2\end{array}$

20. Do you have problems doing home activities (cooking, cleaning, fixing things, etc.)?

$\begin{array}{lll}0.681 & 0.072 & 0.6\end{array}$

21. Do you have problems feeding yourself?

$\begin{array}{lll}-0.006 & 0.489 & -0.5\end{array}$

22. Do you have problems keeping your checkbook, accounts, payments, etc.?

$0.683-0.075 \quad 0.6$

23. Are you more rigid in your decisions, with less capacity to adapt to new situations?

$\begin{array}{lll}0.106 & 0.584 & -0.5\end{array}$

24. Are you more egotistic, paying less attention to other people's needs?

$-0.081 \quad 0.690 \quad-0.6$

25. Are you more irritated? Do you easily lose your temper?

$\begin{array}{lll}0.023 & 0.681 & -0.6\end{array}$

26. Do you have crying episodes?

$\begin{array}{lll}-0.152 & 0.409 & -0.3\end{array}$

27. Do you laugh in inappropriate situations?

$-0.134 \quad 0.551 \quad-0.4$

28. Are you more interested in sexual themes, talking or reading about sex?

$\begin{array}{lll}-0.286 & 0.577 \quad-0.3\end{array}$

29. Have you lost interest in hobbies or activities you used to like?

$\begin{array}{lll}0.363 & 0.276 \quad 0.1\end{array}$

30. Do you feel more depressed?

$\begin{array}{lll}0.129 & 0.227 \quad-0.1\end{array}$

*Dif. $=$ difference in absolute values. 


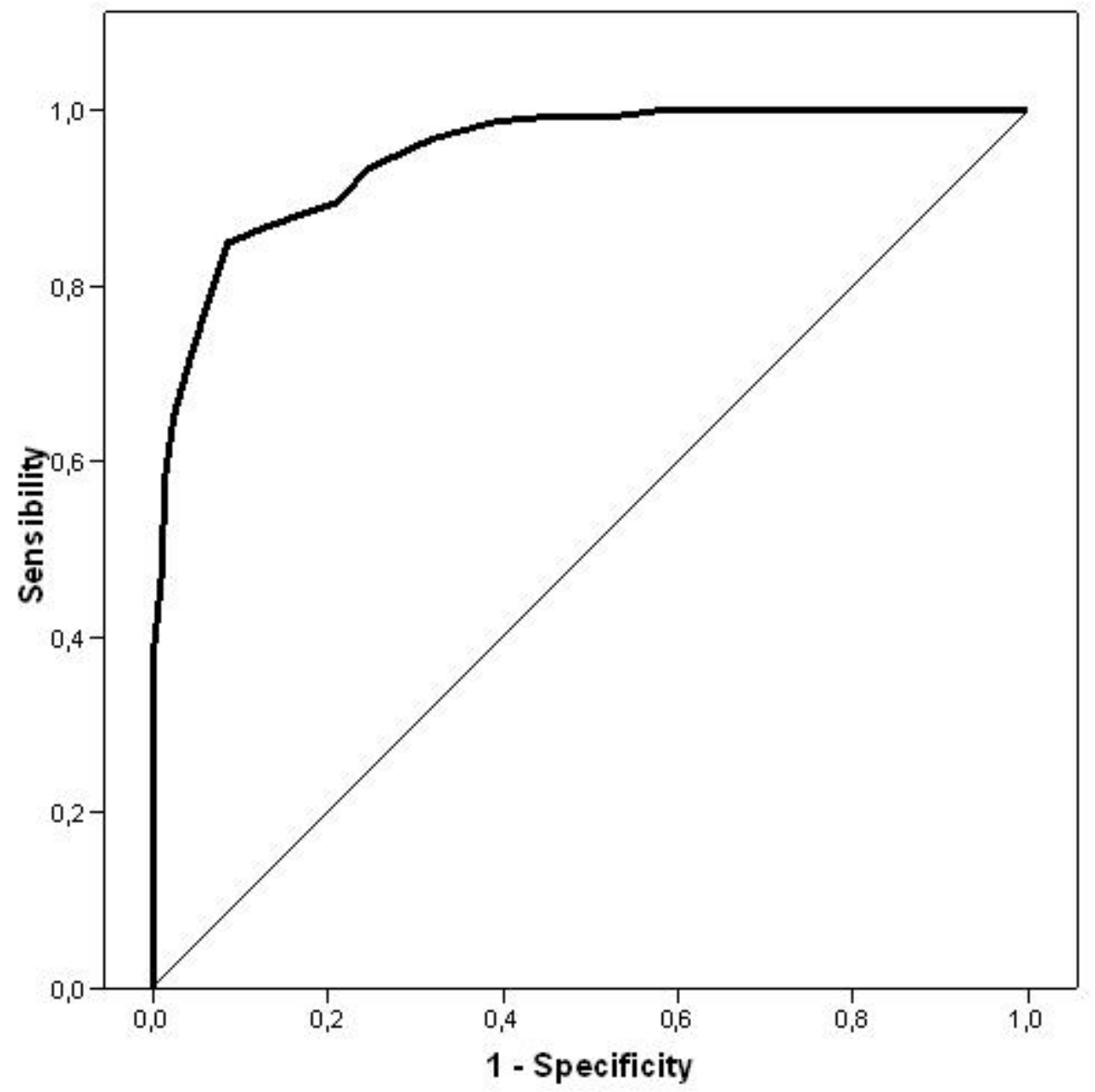

Figure 1. Graphical representation of the area under ROC curve for the AAQ. 